\title{
challenges
}

ISSN 2078-1547

www.mdpi.com/journal/challenges

Review

\section{Carbon Nanotubes in Electronics: Background and Discussion for Waste-Handling Strategies}

\section{Sergio Manzetti ${ }^{1}$ and Otto Andersen ${ }^{2, *}$}

1 FJORDFORSK Environmental Health and Technology, 6896 Fresvik, Sogn og Fjordane, Norway

2 Western Norway Research Institute. Fosshaugane Campus, 6851 Sogndal, Norway

* Author to whom correspondence should be addressed; E-Mail: Otto.Andersen@vestforsk.no.

Received: 26 February 2013; in revised form: 12 March 2013 / Accepted: 24 April 2013 /

Published: 7 May 2013

\begin{abstract}
Carbon nanotubes (CNTs) are increasingly being used in electronics products. CNTs have unique chemical and nanotoxicological properties, which are potentially dangerous to public health and the environment. This report presents the most recent findings of CNTs' toxicity and discusses aspects related to incineration, recycling and potential remediation strategies including chemical and biological remediation possibilities. Our analysis shows that recycling CNTs may be challenging given their physiochemical properties and that available strategies such as power-gasification methods, biological degradation and chemical degradation may need to be combined with pre-handling routines for hazardous materials. The discussion provides the background knowledge for legislative measures concerning specialized waste handling and recycling procedures/facilities for electronics products containing CNTs.
\end{abstract}

Keywords: carbon nanotubes; degradation; incineration; biological; chemical; waste handling; methods

\section{Introduction}

Carbon Nano Tubes (CNTs) are entirely composed of carbon in their original unmodified state. They have diameters in the range of 1-100 nm and length up to a few millimeters. CNTs have unique 
physiochemical properties, including semi-conducting and metallic electrical behavior, high mechanical strength and unique chemical and surface properties, as addressed by main contributors to this field [1-7]. Applications for CNTs span wide areas, including microelectronic devices, catalysis, sensors, high-strength composites, and adsorbents [8-15]. In the fields of bionanotechnology, nanoelectronics, and material sciences, CNTs are utilized as damage-sensors, where for instance their electrical properties are used to detect cracks and physical stress in materials [16]. Damage sensors using CNTs could be applied in automotive vehicles and aerospace constructions in the future, increasing the presence of carbon nanotubes in the environment, and thus the need for relevant waste handling policies.

Other recent applications are the use of CNTs as storage structures in lithium batteries; here the CNTs are combined with graphene sheets in order to provide solid energy-storing nano-ensembles [17]. In the future, the use of graphene in LED lights may come to replace indium-tin alloy-based LEDs due to the lower cost of graphene and poor availability of Indium [18]. Given the ongoing search for green energy solutions, as these two examples of consumer electronics shows, the future use of CNTs are likely to grow fast. CNTs are also widely used in nanoarchitectures, for example; in assembly with DNA [19], and for biosensing purposes to detect ultra-low levels of biomolecules in medical and laboratory samples [20]. In addition, CNTs are frequently used as fortifying components in biopolymers and nanocomposites [21].

CNTs are subdivided into two main classes, single walled carbon nano tubes (SWCNT) and multi-walled carbon nano tubes (MWCNT). SWCNTs can be considered as a single sheet of graphene, which is rolled into a cylinder with diameter of $1 \mathrm{~nm}$ and length of up to several millimeters. MWCNT consist of two or more such cylinders formed coaxially. MWCNTs can have diameters from 2 to 100 $\mathrm{nm}$ and lengths of a few micrometers and be composed of tens of layers [22]. MWCNTs have a stronger physical durability compared with SWCNTs [23].

\section{Environmental and Toxicological Aspects of Carbon Nanotubes}

Environmental remediation of CNTs is a technological feat that may encounter a series of obstacles. The generation of nanoparticles during the waste handling and processing may present challenges. Reports show that nanoparticles can be deposited at locations very distant from their original source, even as far as the Arctic and remote regions of the Pacific Ocean [24,25]. These environmental pollutants have consequently induced significant problems for organisms and animals in untouched habitats. The majority of these particles derive from naturally oxidized plastic components, traffic exhaust emissions, and leakages from industry and other man-made sources. CNTs are not yet a major constituent of this group of contaminants. However, in the near future, it is likely that CNTs will contribute more to this concern, with a similar impact as we have seen with plastics [26]. In this scenario, CNTs increasingly accumulate in the environment, and due to their small size, become integrated into the nutritional and reproductive environment of humans and animals [27].

CNTs, which have many physical characteristics similar to plastics, represent a group of solid and ultra-stable nanoparticles with strong adsorptive properties, binding various molecules and biomolecules efficiently. CNTs have also been shown to interfere with living organisms, to pose health risks and cause genotoxicity, mortality and cellular damage as aerosol or hydrosol particles [28-38]. At the critical end of the spectrum, recent aquatic studies on CNTs show induced 
organ pathology disturbance of respiratory function in rainbow trout, as well as causing terminal effects on mono-cellular aquatic organisms [34,36]. Furthermore, severe damage to mice has been shown [5,31-33,35,37-39], where more violent reactions than asbestos and carbon black were observed [38].

CNTs do not easily degrade. This is a key problem for end-of-life treatment. As such, CNTs constitute similar problematics as asbestos [40,41]. However, attempts at degradation of CNTs by horseradish peroxidase combined with peroxide have been made [42]. Although relevant, these chemical/biochemical conditions do not reflect natural conditions found in the environment. The resistance to degradation is a key issue, which must be taken into consideration when developing strategies for future waste handling om materials containing CNTs. For this reason, life cycle assessment (LCA) studies and remedies for waste handling of CNTs are increasingly being sought. European legislative authorities are increasingly focusing on products containing carbon nano materials, utilizing environmental studies as basis for developing new regulations $[43,44]$.

In light of the emergence of this grave problem, there is an urgent need for a complete human and ecotoxicological assessment of CNTs. Multitudes of different chemical variants derived from pristine CNTs are being synthesized and increasingly phased into society through new consumer products. These compounds will end up as a serious waste problem [8-15].

\section{CNTs in the Environment}

The magnitude of the presence of CNTs in the environment is not well known. However, in 2009, it was estimated an average concentration from anthropogenic sources of $0.003-0.02 \mathrm{ng} / \mathrm{kg}$ soil [45]. In addition to this modeled concentration, an unknown amount of naturally occurring CNTs and fullerenes are found in glaciers, volcano ash and soil [46]. Even though the estimated amount of CNTs in circulation does not appear to present any ecotoxicological threat to the environment, this is strongly contrasted by findings in aquatic species [34,36].

The prevalence of CNTs in the environment is increasing due to the rapid pace of CNTs being introduced into consumer products, also made possible by the lowering of the cost for producing these materials $[45,47,48]$. In 2008, it was estimated that a yearly global production of CNTs of 350 tons, of which $50 \%$ was assumed to be incorporated into consumer electronics and $50 \%$ into plastic products [47]. It can be presumed that the CNTs not being land-filled are being taken to incineration plants, where partial and full incineration of CNTs occurs. In these plants, there is a risk of CNTs being released to air and soil, as a result of their incomplete incineration.

The yearly deposition of CNTs in the environment was in 2008 assumed to be more than 150 tons, and rapidly increasing $[39,47,49]$. With this basis, there is an evident need for CNT recycling strategies to be developed. However, the impact of CNTs for human health must also be assessed in this context.

\section{Recycling Aspects and Strategies for CNTs}

An important aspect of CNTs is their "super-aerosol" property in their pre-fabricated state, making them behave as nanoparticles that easily stick to surfaces, very unlike the behavior of carbon black. This is due to the different electrostatic properties of these two types of nanoparticles $[49,50]$. Carbon 
black subdivides into more or less round particles while CNTs aggregate into rope-like fibers, with similarities to asbestos [39-41,49]. CNTs are increasingly being used in vehicles [50], consumer products [51] and microelectronics [17,18]. During their life time, the general wear and tear during eventual waste handling of the products may release CNT as rod-like nanoparticles [39-41,49]. Even though the amount of CNTs, in the form of particles emitted into the environment, is not known, a precautionary approach should be applied to avoid releases during the waste handling.

Impurities from the CNT production process may pose an additional danger. The metals nickel, yttrium, cobalt and copper are toxic, and may be released during the waste treatment. Metals can be found at significant percentages in CNTs, adding up quickly to several hundred tonnes being released each year $[39,47]$.

\section{Aspects for Incineration Processes}

Incineration of carbon nanoproducts, as a strategy for their waste handling, may also present important dangers. CNTs are highly thermo-stable. Conventional incineration temperatures of 800-900 ${ }^{\circ} \mathrm{C}$ may not be sufficient to obtain complete combustion of CNTs into biodegradable carbon products. Even though Sobek and Bucheli [52] claim that CNTs breaks down at temperatures above $500{ }^{\circ} \mathrm{C}$, parts of their molecular structure is intact at temperatures above $1300{ }^{\circ} \mathrm{C}$ [53]. This is supported by information that CNTs remain structurally stable at $950{ }^{\circ} \mathrm{C}$ (Personal communication, Johan Liu, Chalmers University of Technology, Sweden), and that CNTs are reported to be partly resistant to conventional incineration [54]. Consequently, there is a need to investigate efficient incineration methods for CNTs, as well as land-filling of the incineration ash. These aspects are relevant with polycyclic aromatic hydrocarbons (PAHs) and their biopersistant properties. PAHs are not fully oxidized during combustion, leading to deposition on soil and vegetation, accumulating in sediments and living organisms [55], so that the formation of PAHs from the combustion of CNTs will is thus an expected scenario, with different ratios of heavy and middle weight PAHs than from natural sources such as forest fires and volcanic eruptions.

During incineration, PAHs are normally retained in the gas filters. However, a key problem may be the presence of semi-combusted CNTs in the bottom ash and filter ash with the potential for release into the environment from the subsequent final land-filling of the ash.

It is thus an open question if conventional incineration strategies are effective enough for bringing carbon nanotubes back to their native carbonic state.

\section{Options for Recycling CNTs}

Establishing a proper recycling and waste handling strategy is dependent on that alternative ways from the existing ways of waste-handling are being explored for CNTs. An overview of the discussed options is shown in Figure 1. 
Figure 1. Handling and recycling strategies for electronics containing CNTs. Alternative routes for handling discarded CNT-containing products, with focus on breaking down CNTs.

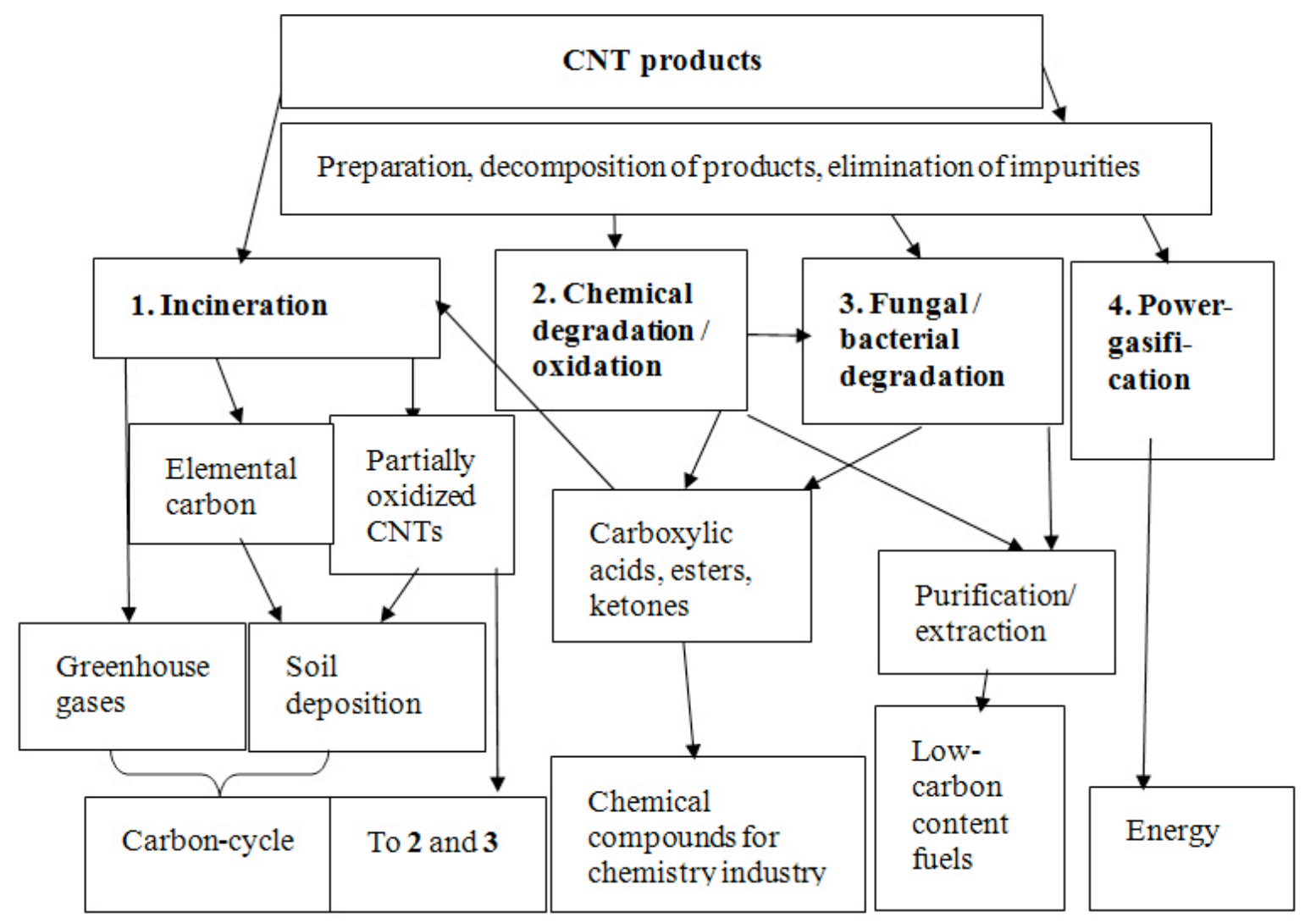

Before the degradation processes are considered, the disassembly of CNT-containing consumer products requires manual force. Such a process requires masks, goggles and protective wear due to the potential risk of CNT materials releasing nanoparticles during the process.

The next step is the removal of metal, with particular focus on the heavy metals [56]. As an end stage of the process, chemical degradation and microbiological degradation are options. An optimal dispersion of CNTs into a solution is necessary, and this can be conducted through sonication of the granulated material containing CNTs. Studies have shown that CNTs are more uniformly dispersed in solutions using sonic dispersion rather than stirring in the dust-state [57,58]. Following sonication, ozonation can be used to convert CNT products into smaller compounds, similar to what is seen with large oxidized PAHs [59]. However, this depends ultimately on what condition the CNT is in, e.g., intact, dust-like particles or partly degraded.

For further decomposition of the oxidized fragments, the method of applying Fenton's reagent reaction and sono-chemical degradation can be used [60]. This has been shown to degrade PAHs under catalyzed conditions using transition state metals, such as nickel or chrome [61]. These methods are applicable if CNTs are sufficiently dispersed in aqueous solutions first, which may be a challenge, particularly when treating CNTs in automobiles and microelectronics.

A second set of chemical conversion alternatives is the use of strong oxidizers, such as permanganates. The disadvantage of this method lies in the emissions generated. Biological methods 
are more environmentally friendly methods and can, with basis in studies on microbial and fungal degradation of PAHs, be considered instead $[61,62,64,66]$. Such methods have limitations for larger PAHs (more than 7 benzene rings), which CNTs supersede in size. A biological degradation preceded by chemical decomposition may, for that reason, be required, and would involve CNTs being pre-ozonated, as has been done for PAHs [59]. Fungal / bacterial degradation of large and medium size PAHs have been published [61-65], in particular using the fungi Phanerochaete [64]. These methods can therefore be combined with the chemical treatment mentioned, precessed by decomposition of CNTs into smaller fragments first. Direct bacterial/fungal degradation of CNTs, without pre-oxidation or chemical treatment, has not been shown [63]. However, taking into account recent findings on the degradation of multi-walled carbon nanotubes, using horseradish peroxidase in combination with hydrogen peroxide [66], a combination of bacterially produced peroxidase in combination with peroxide, may represent a viable biochemical method.

A different option is the use of power-gasification methods, which are increasingly being studied for potential use in waste treatment. However, still in their infancy, such methods are debated because of the environmental challenges they need to overcome. Waste products, such as discarded coal, are used for the generation of energy, but this emits greenhouse gases. Discarded CNTs may be considered handled by such methods as well, as investigated by Koukouzas et al. [65]. However, very few projects world-wide include handling of waste coal and biomass for co-gasification, but they may however be included in future alternatives, with $\mathrm{CO}_{2}$ capture, if sufficiently management of greenhouse emissions occurs.

An important aspect of recycling is thus related to the emissions being released. Life cycle assessments are necessary to provide the basis for any recycling strategy of CNTs [67].

\section{Conclusions}

The knowledge of future carbon nanotube recycling and waste treatment is important to develop in context of the rapid increase in use of CNTs in consumer products $[39,47]$. This is due to their toxic properties, and lowering of costs leading to their higher application and consumption. The dangers from the increased presence of CNTs in society is aggravated by the potential implication of the practice of converting polyethylene-based used plastics into CNTs [68]. Although plastics are often considered as the modern age's peril, a replacement by carbon nanotubes may encounter several obstacles, as here described. Through this paper, it is hoped that this discussion on the impacts and handling of these technologies will stimulate the discovery of viable solutions to the emerging problem of CNT waste remediation.

\section{References and Notes}

1. Iijima, S. Helical microtubules of graphitic carbon. Nature 1991, 354, 56-58.

2. Ugarte, D. Curling and closure of graphitic networks under electron-beam irradiation. Nature 1992, 359, 707-709.

3. Ghadiri, M.R.; Granja, J.R.; Milligan, R.A.; McRee, D.E.; Khazanovich, N. Self-assembling organic nanotubes based on a cyclic peptide architecture. Nature 1993, 366, 324-327. 
4. Iijima, S.; Ichihashi, T. Single-shell carbon nanotubes of 1-nm diameter. Nature 1993, 363, 603-605.

5. Ajayan, P.M.; Stephan, O.; Colliex, C.; Trauth, D. Aligned carbon nanotube arrays formed by cutting a polymer resin--nanotube composite. Science 1994, 265, 1212-1214.

6. Falvo, M.R.; Clary, G.J.; Taylor, R.M., 2nd; Chi, V.; Brooks, F.P.J.; Washburn, S.; Superfine, R. Bending and buckling of carbon nanotubes under large strain. Nature 1997, 389, 582-584.

7. Andrae, A.; Andersen, O. Life cycle assessment of integrated circuit packaging technologies. Int. J. Life Cycle Ass. 2011, 16, 258-267.

8. Bethune, D.S.; Kiang, C.H.; Devries, M.S.; Gorman, G. Cobalt-catalysed growth of carbon nanotubes with single-atomic-layer walls. Nature 1993, 363, 605-607.

9. Wood, J.R.; Zhao, Q.; Frogley, M.D.; Meurs, E.R.; Prins, A.D.; Peijs, T. Carbon nanotubes: From molecular to macroscopic sensors. Phys. Rev. B 2000, 62, 7571-7575.

10. Dillon, A.C.; Heben, M.J. Hydrogen storage using carbon adsorbents: Past, present and future. Appl. Phys. A 2001, 72, 133-142.

11. Thostenson, E.T.; Ren, Z.F.; Chou, T.W. Advances in the science and technology of carbon nanotubes and their composites: A review. Compos. Sci. Technol. 2001, 61, 1899-1912.

12. Avouris, P. Carbon nanotube electronics. Chem Phys 2002, 281, 429-445.

13. Landi, B.J.; Raffaelle, R.P.; Heben, M.J.; Alleman, J.L.; VanDerveer, W.; Gennett, T. Single-wall carbon nanotube-Nafion composite actuators. Nano Lett. 2002, 2, 1329-1332.

14. Li, W.Z.; Liang, C.H.; Qiu, J.S.; Zhou, W.J.; Han, H.M.; Wie, Z.B. Carbon nanotubes as support for cathode catalyst of a direct methanol fuel cell. Carbon 2002, 40, 791-794.

15. Hata, K.; Futaba, D.N.; Mizuno, K.; Namai, T.; Yumura, M.; Iijima, S. Water-assisted highly efficient synthesis of impurity-free singlewalled carbon nanotubes. Science 2004, 306, 1362-1364.

16. De Villoria, R.; Yamamoto, N.; Miravete, A.; Wardle, B. Multi-physics damage sensing in nano-engineered structural composites. Nanotechnology 2011, 22, 185502.

17. Fan, Z.; Yan, J.; Wie, T.; Zhi, L.; Wei, F. Nanographene-constructed carbon nanofibers grown on graphene sheets by chemical vapor deposition: High-performance anode materials for lithium ion batteries. ACS Nano 2011, 5, 2787-2794.

18. Matyba, P.; Yamaguchi, H.; Eda, G.; Chhowalla, M.; Edman, L.; Robinson, N. Graphene and mobile ions: The key to all-plastic, solution-processed light-emitting devices. ACS Nano 2010, 4, 637-642.

19. Eskelinen, A.; Kuzyk, A.; Kaltiaisenaho, T.; Timmermans, M.; Nasibulin, A.; Kaupppinen, E.; Törmä, P. Assembly of single-walled carbon nanotubes on DNA-origami templates through streptavidin-biotin interaction. Small 2011, 7, 746-750.

20. Chen, Z.; Zhang, X.; Yang, R.; Zhu, Z.; Chen, Y.; Tan, W. Single-walled carbon nanotubes as optical materials for biosensing. Nanoscale 2011, 3, 1949-1956.

21. Lu, L.; Chen, W. Supramolecular self-assembly of biopolymers with carbon nanotubes for biomimetic and bio-inspired sensing and actuation. Nanoscale 2011, 3, 2412-2420.

22. Colbert, D.; Zhang, J.; McClure, S.; Nikolaev, P.; Chen, Z.; Hafner, J.; Owens, D.; Kotula, P.; Carter, C.; Weaver, J.; Rinzler, A.; Smalley, R. Growth and sintering of fullerene nanotubes. Science 1994, 266, 1218-1222. 
23. Kociak, M.; Suenaga, K.; Hirahara, K.; Saito, Y.; Nakahira, T.; Iijima, S. Linking chiral indices and transport properties of double-walled carbon nanotubes. Phys. Rev. Lett. 2002, 89, 155501-155504.

24. Kumar, N.; Shah, V.; Walker, V. Perturbation of an arctic soil microbial community by metal nanoparticles. J. Hazard Mater. 2011, 190, 816-822.

25. Doyle, M.; Watson, W.; Bowlin, N.; Sheavly, S. Plastic particles in coastal pelagic ecosystems of the Northeast Pacific ocean. Mar. Environ. Res. 2011, 71, 41-52.

26. Walsh, B. The Perils of Plastic. Time Magazine April 1, 2010.

27. Velzeboer, I.; Kupryianchyk, D.; Peeters, E.; Koelmans, A. Community effects of carbon nanotubes in aquatic sediments. Environ. Int. 2011, 37, 1126-1130.

28. Atha, D.H.; Wang, H.H.; Petersen, E.J.; Cleveland, D.; Holbrook, R.D.; Jaruga, P.; Dizdaroglu, M.; Xing, B.; Nelson, B.C. Copper oxide nanoparticle mediated DNA damage in terrestrial plant models. Environ. Sci. Technol. 2012, 46, 1819-1827.

29. Nakanishi, J. Risk Assessment of Manufactured Nanomaterials: Carbon nanotubes (CNT); Final report issued on 12 August 2011, NEDO project (P06041); New Energy and Industrial Technology Development Organization: Kawasaki, Japan, 2011.

30. Lam, C.-W.; James, J.; McCluskey, R.; Arepalli, S.; Hunter, R. A review of carbon nanotube toxicity and assessment of potential occupational and environmental health risks. Crit. Rev. Toxicol. 2006, 36, 189-217.

31. Shvedova, A.; Kisin, E.; Mercer, R.; Murray, A.; Johnson, V.; Potapovich, A.; Tyurina, Y.; Gorelik, O.; Arepalli, S.; Schwegler-Berry, D.; Hubbs, A.; Antonini, J.; Evans, D.; Ku, B.; Ramsey, D.; Maynard, A.; Kagan, V.; Castranova, V.; Baron, P. Unusual inflammatory and fibrogenic pulmonary responses to single-walled carbon nanotubes in mice. Am. J. Physiol. Lung Cell Mol. Physiol. 2005, 289, 698-708.

32. Shvedova, A.; Kisin, E.; Murray, A.; Gorelik, O.; Arepalli, S.; Castranova, V.; Young, S.; Gao, F.; Tyurina, Y.; Oury, T.; Kagan, V. Vitamin E deficiency enhances pulmonary inflammatory response and oxidative stress induced by single-walled carbon nanotubes in C57BL/6 mice. Toxicol. Appl. Pharmacol. 2007, 221, 339-348.

33. Shvedova, A.; Kisin, E.; Murray, A.; Johnson, V.; Gorelik, O.; Arepalli, S.; Hupps, A.; Mercer, R.; Keohavong, P.; Sussman, N.; Jin, J.; Yin, J.; Stone, S.; Chen, B.; Deye, G.; Maynard, A.; Castranova, V.; Baron, P.; Kagan, V. Inhalation vs. aspiration of single-walled carbon nanotubes in C57BL/6 mice: Inflammation, fibrosis, oxidative stress, and mutagenesis. Am. J. Physiol. Lung Cell Mol. Physiol. 2008, 295, 552-565.

34. Smith, C.; Shaw, B.; Handy, R. Toxicity of single walled carbon nanotubes to rainbow trout, (Oncorhynchus mykiss): Respiratory toxicity, organ pathologies, and other physiological effects. Aquat. Toxicol. 2007, 82, 94-109.

35. Vogel, S.; Kappes, M.; Hennrich, F.; Richert, C. An unexpected new optimum in the structure space of DNA solubilizing single-walled carbon nanotubes. Chemistry 2007, 13, 1815-1820.

36. Kwok, K.; Leung, K.; Flahaut, E.; Cheng, J.; Cheng, S. Chronic toxicity of double-walled carbon nanotubes to three marine organisms: Influence of different dispersion methods. Nanomedicine (London) 2010, 5, 951-961. 
37. Shvedova, A.; Kagan, V. The role of nanotoxicology in realizing the "helping without harm" paradigm of nanomedicine: Lessons from studies of pulmonary effects of single-walled carbon nanotubes. J. Intern. Med. 2010, 267, 106-118.

38. Teeguarden, J.; Webb-Robertson, B.; Waters, K.; Murray, A.; Kisin, E.; Varnum, S.; Jacobs, J.; Pounds, J.; Zanger, R.; Shvedova, A. Comparative proteomics and pulmonary toxicity of instilled single-walled carbon nanotubes, crocidolite asbestos, and ultrafine carbon black in mice. Toxicol. Sci. 2011, 120, 123-135.

39. Lam, C.-W.; James, J.; McCluskey, R.; Hunter, R. Pulmonary toxicity of single-wall carbon nanotubes in mice 7 and 90 days after intratracheal instillation. Toxicol. Sci. 2004, 77, 126.

40. Kane, A.; Hurt, R. Nanotoxicology: The asbestos analogy revisited. Nat. Nanotechnol. 2008, 3, 378-379.

41. Jaurand, M.; Renier, A.; Daubriac, J. Mesothelioma: Do asbestos and carbon nanotubes pose the same health risk? Part. Fibre Toxicol. 2009, 6, 16.

42. Allen, B.; Kichambare, P.; Gou, P.; Vlasova, I.; Kapralov, A.; Konduru, N.; Kagan, V.; Star, A. Biodegradation of single-walled carbon nanotubes through enzymatic catalysis. Nano Lett. 2008 , 8, 3899-3903.

43. Hunt, G. The Labelling "Nano-products"-Update February 2011. In Proceedings of Products, Privacy \& People: Regulating at the Nanoscale, House of Lords, London, UK, 28 February 2011; BioCentre: London, UK, 2011.

44. European Commission. Opinion on the appropriateness of the risk assessment methodology in accordance with the technical guidance documents for new and existing substances for assessing the risks of nanomaterials. Scientific Committee on Emerging and Newly-Identified Health Risks (SCENIHR), Health \& Consumer Protection Directorate-General: Brussels, Belgium, 2011.

45. Gottschalk, F.; Sonderer, T.; Scholz, R.; Nowack, B. Modeled environmental concentrations of engineered nanomaterials (TiO2, $\mathrm{ZnO}, \mathrm{Ag}, \mathrm{CNT}$, fullerenes) for different regions. Environ. Sci. Technol. 2009, 43, 9216-9222.

46. Murr, L.; Esquivel, E.; Bang, J.; de la Rosa, G.; Gardea-Torresdey, J. Chemistry and nanoparticulate compositions of a 10,000 year-old ice core melt water. Water Res. 2004, 38, 4282-4296.

47. Mueller, N.; Nowack, B. Exposure modeling of engineered nanoparticles in the environment. Environ. Sci. Technol. 2008, 42, 4447-4453.

48. Koelmans, A.; Nowack, B.; Wiesner, M. Comparison of manufactured and black carbon nanoparticle concentrations in aquatic sediments. Environ. Pollut. 2009, 157, 1110-1116.

49. Salvetat, J.-P.; Bonard, J.-M.; Thomson, N.; Kulik, A.; Forr'o, L. Mechanical properties of carbon nanotubes. Appl. Phys. A 1999, A, 255.

50. Sanera, B.; Dinça, F.; Yürüm, Y. Utilization of multiple graphene nanosheets in fuel cells: 2. The effect of oxidation process on the characteristics of graphene nanosheets. Fuel 2011, 90, 2609-2616.

51. Som, C.; Wick, P.; Krug, H.; Nowack, B. Environmental and health effects of nanomaterials in nanotextiles and façade coatings. Environ. Int. 2011, 37, 1131-1142. 
52. Sobek, A.; Bucheli, T. Testing the resistance of single- and multi-walled carbon nanotubes to chemothermal oxidation used to isolate soots from environmental samples. Environ. Pollut. 2009, 157, 1065-1071.

53. Bom, D.; Andrews, R.; Jacques, D.; Anthony, J.; Bailin Chen, B.; Meier, M.; Selegue, J. Thermogravimetric analysis of the oxidation of multiwalled carbon nanotubes: Evidence for the role of defect sites in carbon nanotube chemistry. Nano Lett. 2002, 2, 615-619.

54. Vignes, A.; Dufaud, O.; Perrin, L.; Thomas, D.; Bouillard, J.; Janès, A.; Vallières, C. Thermal ignition and self-heating of carbon nanotubes: From thermokinetic study to process safety. Chem. Eng. Sci. 2009, 64, 4210-4221.

55. Liu, G.; Niu, Z.; Van Niekerk, D.; Xue, J.; Zheng, L. Polycyclic aromatic hydrocarbons (PAHs) from coal combustion: Emissions, analysis, and toxicology. Rev. Environ. Contam. Toxicol. 2008, 192, 1-28.

56. Modina, H.; Perssona, K.; Andersson, A.; van Praaghe, M. Removal of metals from landfill leachate by sorption to activated carbon, bone meal and iron fines. J. Hazard. Mater. 2011, 189, 749-754.

57. Kennedy, A.; Hull, M.; Steevens, J.; Dontsova, K.; Chappell, M.; Gunter, J.; Weiss, C.J. Factors influencing the partitioning and toxicity of nanotubes in the aquatic environment. Environ. Toxicol. Chem. 2008, 27, 1932-1941.

58. Barnard, D. Sonochemical degradation of PAH in aqueous solution. Part I: Monocomponent PAH solution. Ultrason. Sonochem. 2009, 16, 260-265.

59. Álvarez, P.; García-Araya, J.; Beltrán, F.; Masa, F.; Medina, F. Ozonation of activated carbons: Effect on the adsorption of selected phenolic compounds from aqueous solutions. J. Colloid Interface Sci. 2005, 283, 503-512.

60. Jonsson, S.; Persson, Y.; Frankki, S.; van Bavel, B.; Lundstedt, S.; Haglund, P.; Tysklind, M. Degradation of polycyclic aromatic hydrocarbons (PAHs) in contaminated soils by Fenton's reagent: A multivariate evaluation of the importance of soil characteristics and PAH properties. $J$. Hazard. Mater. 2007, 149, 86-96.

61. Zhang, X.; Cheng, S.; Zhu, C.; Sun, S. Microbial PAH-degradation in soil: Degradation pathways and contributing factors. Pedosphere 2006, 16, 555-565.

62. Johnsen, A.; Wick, L.; Harms, H. Principles of microbial PAH-degradation in soil. Environ. Pollut. 2005, 133, 71-84.

63. Bianco, A.; Kostarelos, K.; Prato, M. Making carbon nanotubes biocompatible and biodegradable. Chem. Commun. (Camb). 2011, 47, 10182-10188.

64. Yan, J.; Cheng, S.; Zhang, X.; Shi, L.; Zhu, J. Effect of four metals on the degradation of purified terephthalic acid wastewater by Phanaerochaete chrysosporium and strain Fhhh. Bull. Environ. Contam. Toxicol. 2004, 72, 387-393.

65. Koukouzas, N.; Katsiadakis, A.; Karlopoulos, E.; Kakaras, E. Co-gasification of solid waste and lignite-A case study for Western Macedonia. Waste Manag. 2008, 28, 1263-1275.

66. Zhao, Y.; Allen, B.; Star, A. Enzymatic degradation of multiwalled carbon nanotubes. J. Phys. Chem. A 2011, 115, 9536-9544. 
67. Meyer, D.; Curran, M.; Gonzalez, M. An examination of existing data for the industrial manufacture and use of nanocomponents and their role in the life cycle impact of nanoproducts. $J$. Environ. Tech. 2009, 43, 1256-1263.

68. Pol, V.; Thivagarajan, P. Remediating plastic waste into carbon nanotubes. J. Environ Monit. 2010, 12, 455-459.

(C) 2013 by the authors; licensee MDPI, Basel, Switzerland. This article is an open access article distributed under the terms and conditions of the Creative Commons Attribution license (http://creativecommons.org/licenses/by/3.0/). 